\title{
Green tobacco sickness
}

Jeffrey S McBride, David G Altman, Melissa Klein, Wain White

\begin{abstract}
Objective-To describe the health impact of harvesting tobacco and to suggest prevention and risk reduction strategies to avoid contracting green tobacco sickness (GTS).
\end{abstract}

Data sources-A literature search of Medline, Toxline, and Toxline65 with the terms "green", "tobacco", and "sickness" covering the years 1966-1998.

Study selection-All studies, reviews, and commentaries that provided information on the health effects of harvesting green tobacco and disease prevention strategies. Data synthesis-GTS occurs when tobacco workers hand-harvest, cut, or load tobacco plants, usually in the early morning or after a rainfall when tobacco plants are covered with moisture. GTS occurs through skin exposure to dissolved nicotine from tobacco leaves. Symptoms of GTS include weakness, headache, nausea, vomiting, dizziness, abdominal cramps, breathing difficulty, abnormal temperature, pallor, diarrhoea, chills, fluctuations in blood pressure or heart rate, and increased perspiration and salivation. The onset of the illness is three to 17 hours after exposure and the duration of illness is one to three days. Initial treatment includes cessation of work, change of clothing, showering, fluid intake, and rest. In more extreme cases, intravenous rehydration, anti-emetics, and dimenhydrinate are administered. Protective, water-resistant clothing; chemical-resistant gloves, boots, and socks; working in dry conditions; and dimenhydrinate can reduce the likelihood of contracting GTS.

Conclusions-It is important to provide education to tobacco workers and employers about GTS. An international public awareness campaign about GTS timed to coincide with the tobacco harvest, along with enforced worker safety regulations, should be undertaken to protect the health of individuals working in tobacco production.

(Tobacco Control 1998;7:294-298)

Keywords: green tobacco sickness, health education, occupational safety

Correspondence to: University School of

Medicine, Department

Public Health Sciences

Medical Center Boulevard,

Winston-Salem, North

Carolina 27157-1063, USA

daltman@rc.phs.wfubmc.edu

Introduction

The health risks associated with smoking tobacco and exposure to secondhand smoke are well known. Less well known are the health effects of handling wet tobacco leaves. Green tobacco sickness (GTS) is a form of nicotine poisoning that affects workers who have direct contact with tobacco plants during cultivation and harvesting. Symptoms of GTS are similar to those induced by pesticide exposure or heat exhaustion, and to nicotine intoxication experienced by novice smokers. Thus, GTS may be misdiagnosed by practitioners unfamiliar with this condition. ${ }^{1-4}$ Although GTS has not been associated with mortality or long-term morbidity, it causes significant discomfort and lost productivity among tobacco workers. ${ }^{14-8}$

Much of the research on GTS has focused on American tobacco harvesters. Internationally, the effects and prevalence of GTS are not well known. Foreign production of tobacco, however, has increased rapidly in recent years and tobacco manufacturers and wholesalers spend millions of dollars each year helping foreign tobacco growers with state-of-the art technology, growing techniques, seeds, fertilisers, chemicals, and leaf-processing plants. ${ }^{9} 10$ As a result of this shift in the world tobacco supply, we may see a subsequent shift in the distribution of GTS.

In the United States, there have been published reports of GTS in Kentucky, ${ }^{237}$ Florida, ${ }^{11}$ Tennessee, ${ }^{4}$ and North Carolina. ${ }^{1}$ Internationally, GTS has been recorded in India $^{5}$ and Japan. ${ }^{12}$ Although much has been learned about GTS in the United States over the past 20 years, very little regulatory effort has been undertaken to address the potential hazards of this disease.

Data sources and study selection

All population-based studies, review articles, and commentaries concerning GTS were included, although literature on GTS is sparse. GTS is not included in several of the most well-known medical dictionaries-for example, Stedman's, Churchill's, Dorland's - and only 18 journal articles were found in a comprehensive literature search covering the years 1966-1998. This search of Medline, Toxline, and Toxline65 used the terms "green", "tobacco", and "sickness." To find additional studies and commentaries, the bibliographies of identified articles were also reviewed.

Data synthesis
SYMPTOMS

During GTS onset, early symptoms often include headache and nausea followed by 
vomiting, weakness, pallor, dizziness, headaches, increased perspiration, chills, abdominal pain, diarrhoea, and increased salivation. ${ }^{1-8}$ 13-17 $^{17}$ These effects can be rather extreme, and may also include severe prostration, ${ }^{31718}$ shortness of breath, and occasional fluctuations in blood pressure or heart rate. ${ }^{13} 13$ Among those susceptible, the average length of the illness, with treatment, is between one and three days (median $=2.4$ days). ${ }^{27}$

Some of the symptoms of GTS are similar to those of organosphosphate poisoning and heat exhaustion. However, many of the symptoms of organosphosphate poisoning (including increased lacrimation, pulmonary oedema, and miosis) have not been associated with GTS. ${ }^{8}$ The possibility that GTS symptoms are due to pesticide poisoning is lessened because the last application of pesticides normally occurs several weeks before harvest. ${ }^{1811}$ and because GTS is known to occur among workers on farms that do not use pesticides. Furthermore, cases of GTS were documented before widespread pesticide use. ${ }^{11}$

Symptoms of heat exhaustion have been ruled out in many cases of GTS. Although tobacco is typically harvested during hot weather, GTS symptoms have also appeared during cool conditions when harvesters reported feeling chilled rather than overheated. ${ }^{1}$ Also, most of those stricken with GTS became ill after they had gone home for the day (median onset $=10$ hours). ${ }^{2}$

\section{AETIOLOGY}

Exposure to nicotine

Burley and flue-cured tobacco are the two main types of tobacco grown in the United States, accounting for $94 \%$ of all tobacco grown. Burley is grown primarily in Kentucky and Tennessee, whereas flue-cured tobacco is grown largely in North Carolina, South Carolina, Virginia, and Georgia. ${ }^{19}$ The amount of nicotine present in a tobacco leaf depends on a number of factors including genetics, soil, fertilisation practices, weather, and cultivation and harvesting techniques. ${ }^{80}$ On average, burley tobacco contains about $13 \%$ more nicotine than flue-cured tobacco. ${ }^{21}$ Nicotine levels in dark varieties of tobacco-such as dark fire-cured, dark air-cured - are generally higher than burley. ${ }^{22}$

GTS occurs primarily among tobacco workers who hand-harvest ("crop") tobacco leaves in the field and handle the leaves as they are placed in barns for curing. The process of cropping flue-cured tobacco usually consists of pulling and twisting loose green leaves from the plant and collecting them in large bundles that are held either in the hand or underneath the arm and against the body. For burley tobacco, the entire stalk is removed and the tobacco is typically held in the hand or on the forearm. Hand harvesting can lead to skin abrasions, further increasing risk of contracting GTS. Larger farm operators are increasingly using mechanical harvesting equipment, thus reducing dermal exposure to tobacco leaves.
Cropping typically occurs in the summer and autumn months. Workers begin in the early morning, when the tender green tobacco is wet with dew. GTS occurs primarily when people handle wet tobacco. ${ }^{1-3723}$ The geographical clustering of GTS cases is influenced by rainfall, temperature, and humidity. ${ }^{17}{ }^{24}$ In the process of cropping tobacco, leaves and stalks are often cracked, emitting a gummy substance that coats workers' hands, skin, and clothing. ${ }^{11}$ After curing, leaves are usually loaded into burlap sheets in preparation for taking them to the auction market. Some farmers are experimenting with compressed bales of tobacco that can hold substantially more tobacco than a burlap sheet. ${ }^{25}$ Although tobacco is handled during many stages of production, GTS occurs primarily among workers who handle green leaves and stalks in the field or during the process of transferring green tobacco to the curing barn. ${ }^{1}$

\section{Absorption of nicotine}

GTS is a threat to those who harvest tobacco because nicotine, being soluble in water, ${ }^{26} \mathrm{can}$ be drawn out of tobacco by rain, dew, or perspiration, and subsequently absorbed through the skin. ${ }^{5}{ }^{13}$ As much as 9 mg nicotine may be contained in $100 \mathrm{ml}$ of dew. ${ }^{13}$ Although there is no accurate measurement of the amount of nicotine-laden dew to which tobacco harvesters are exposed, Gehlbach and colleagues suggested that $600 \mathrm{ml}$ would be a conservative estimate. ${ }^{13}$ The percentage of dew-laden nicotine absorbed transdermally, however, is not known. Despite this, many studies have documented the increase of cotinine (a nicotine metabolite) in the urine of tobacco workers, after controlling for those who reported regular tobacco usage. ${ }^{513-16}$ Absorption was found to be greatest among croppers who had the most contact with the wet leaves and least among stringers (those who tie burley tobacco leaves on poles for curing) and tractor drivers.

Once the dew-laden tobacco is contacted, croppers can absorb a great deal of nicotine in a relatively short period of time. It has been reported that nausea and faintness can occur within 15 minutes of skin contact, ${ }^{27}$ although the US Centers for Disease Control and Prevention (CDC) reported that the median time from exposure to onset of GTS was 10 hours (ranging from three to 17 hours). ${ }^{2}$

\section{Effects of nicotine}

Once nicotine is absorbed, it is distributed throughout the body, including into the brain. The nausea and vomiting characteristic of GTS is mediated by the direct action of nicotine on the emetic chemoreceptor trigger zone in the medulla oblongata leading to reflex vomiting. ${ }^{28}$ Nicotine also excites sensory nerves from the gut and parasympathetic nerves in the gastrointestinal tract, which lead to an overall increase in gastrointestinal secretion and motility. The pharmacological effects of nicotine on nicotinic receptors in the central nervous system and at post-synaptic autonomic ganglia have been well 
elaborated ${ }^{29}$ and help to explain the toxic effects of nicotine. However, symptoms associated with severe nicotine poisoning, such as convulsions, dyspnoea, and vascular collapse, are not typically seen in GTS cases. ${ }^{1}$ Symptoms that are ascribed to nicotine intoxication in novice smokers mimic green tobacco sickness-for example, nausea, vomiting, increased heart rate, chills.

EPIDEMIOLOGY

A few studies have estimated the incidence of GTS. Using United States and Kentucky Department of Agriculture data, the incidence of GTS was estimated to be 10/1000 workers (or 1\%). ${ }^{3}$ In 1973, a study in North Carolina estimated a $9 \%$ prevalence of GTS -5400 of 60000 workers. ${ }^{1}$ These estimates are not comparable because case numbers were based on self-reported data in North Carolina and on hospital-treated cases in Kentucky. Thus, a true estimate of the prevalence of GTS is difficult to derive because reporting methods are not standardised and many cases likely go unreported.

Younger workers are more likely than older workers to develop GTS. ${ }^{1-3}{ }^{6}$ In one study, 58\% of those suffering GTS were under age 29 and $32 \%$ were between 14 and 19 years of age. ${ }^{6}$ Likewise, it was found that younger people (under age 30) were 3.1 times more likely to develop GTS than older people. ${ }^{3}$ Differences by gender have also been found. ${ }^{16}{ }^{15}$ Nearly all of those affected by GTS are male ${ }^{1615}$ although women do not have any special genetic protection. Sex differences are probably due to the fact that women are largely under-represented among tobacco croppers. ${ }^{2}$

Familial clustering of GTS has also been found. ${ }^{1724}$ This may be less a function of genetic predisposition and more a function of the fact that in regions where there is little mechanisation, such as on small family farms, families or groups of individuals must manually harvest the crop under similar conditions, which in turn may lead to similar exposure patterns. Along these lines, GTS is known to recur among those susceptible to the illness. ${ }^{5}{ }^{711}{ }^{13}$ Gehlbach and colleagues reported that as many as 12 recurrences over eight weeks have been reported by some workers. ${ }^{13}$

There is a discrepancy in the literature between the susceptibility of tobacco users and non-users. In some studies, GTS was found to be less likely to occur among those who were current tobacco users, perhaps resulting from an increased tolerance to the effects of nicotine. ${ }^{13813}$ This seemingly acquired tolerance, however, may not be completely protective if the cropper's typical nicotine exposure is significantly exceeded. ${ }^{235}$ In contrast, a few studies have suggested that active smoking offers no protection against GTS. ${ }^{14}{ }^{15}$ One study found that tobacco users in India actually had a higher prevalence of "green symptoms" than non-tobacco users. ${ }^{14}$

DIAGNOSIS AND TREATMENT

Because GTS is self-limiting and of short duration, ${ }^{1}$ treatment is not always necessary.
Despite the relatively short duration of GTS, the illness can be debilitating during its onset and progression. Clinical diagnosis of GTS is based upon both the presence of symptoms described above and a history of harvesting tobacco. The diagnosis of GTS may be made by testing the blood or urine for nicotine (halflife $=3-4$ hours) or cotinine (a nicotine metabolite (half-life $=36$ hours) that can also be detected in saliva). ${ }^{3}$ Although the level of cotinine has been used to distinguish between tobacco users and non-users, ${ }^{5}{ }^{15} 1623$ the level cannot be used to distinguish between heavy tobacco users and persons with GTS, because nicotine/cotinine concentrations that represent toxic levels have not been established.

Little has been written about the treatment modalities available to those seeking relief from GTS. Although it can take as much as 10 hours before GTS symptoms occur, the most common suggestion once symptoms occur is to avoid increased contact with green tobacco. This can be accomplished by ceasing work, changing clothes, and showering. In addition, exposed workers are encouraged to increase fluid intake, ingest dimenhydrinate (Dramamine), and rest. ${ }^{2618}$ The therapeutic effects of $\mathrm{H} 1$ blockers such as dimenhydrinate, however, are not mediated through an antagonistic action on the nicotinic cholinergic receptors. When symptoms are serious, physicians can administer intravenous hydration, anti-emetics, and H1 blockers (dimenhydrinate). ${ }^{26-8} 18$

Costs

Because nearly a quarter of those stricken with GTS who sought medical treatment required hospitalisation, ${ }^{26}$ significant hospital expenditures are associated with the condition. GTS-induced hospital expenses are estimated to average US $\$ 250$ for outpatient treatment, $\$ 566$ for hospital admission, and $\$ 2041$ for intensive care treatment. ${ }^{2}$ These figures do not include costs associated with lost income and productivity incurred by someone's inability to work. Because nearly half of Kentucky tobacco harvesters are employed off-farm (in work unrelated to farming), ${ }^{6}$ financial loss from missed work due to GTS is compounded further.

RISK REDUCTION

Despite the awareness of GTS among some clinicians and tobacco workers, very little widespread action has been taken to reduce the risks associated with harvesting tobacco. If a worker becomes ill while working with tobacco and requires medical attention, the physician should be informed of the exposure to nicotine to aid in diagnosis, as it is common to misdiagnose GTS as pesticide poisoning or heat exhaustion.

The use of protective, water-resistant clothing and chemical-resistant gloves would reduce the amount of nicotine absorbed by workers in contact with green tobacco. $^{2} 3571415172330$ Current occupational health regulations do not require this level of protection. It has been suggested that croppers 
Green tobacco sickness

\begin{tabular}{|c|c|}
\hline Toxic agent & Nicotiana tabacum (nicotine) \\
\hline Exposure environment & $\begin{array}{l}\text { Tobacco workers hand harvesting, cutting, or loading tobacco plants during harvest; usually (but not necessarily) in the early } \\
\text { morning or after rainfall when tobacco plants are covered with moisture. }\end{array}$ \\
\hline Exposure attributes & $\begin{array}{l}\text { Skin exposure (hands, forearms, thighs, backs, and feet) to dissolved nicotine from wet tobacco leaves. Dew from tobacco leaves } \\
\text { often saturates workers' clothing within minutes of beginning field work. }\end{array}$ \\
\hline \multirow[t]{2}{*}{ Symptoms } & Most common: weakness, headache, nausea, vomiting, dizziness \\
\hline & $\begin{array}{l}\text { Other: abdominal cramps, breathing difficulty, abnormal temperature, pallor, diarrhoea, chills, fluctuations in blood pressure or } \\
\text { heart rate, increased perspiration and salivation }\end{array}$ \\
\hline Illness onset & Range of onset 3-17 hours; median onset 10 hours. \\
\hline Duration of illness (untreated) & Mean duration of the illness is 2.4 days. \\
\hline \multirow[t]{2}{*}{ Treatment } & Self: change clothing, showering, work cessation, fluid intake, rest, time \\
\hline & Medical facility (if needed): Intravenous rehydration, anti-emetics, dimenhydrinate, supportive care \\
\hline Risk reduction & $\begin{array}{l}\text { Protective, water-resistant clothing; chemical-resistant gloves, boots, socks; avoid harvesting during rain or in the early morning; } \\
\text { change clothing if wet; wash clothes if soaked with tobacco sap; dimenhydrinate (treatment and prophylactic); employee } \\
\text { awareness-inform physician about exposure to nicotine. }\end{array}$ \\
\hline Public health response & $\begin{array}{l}\text { Educational outreach (timed to coincide with tobacco harvest) - informational mailings, flyers, bulletins, and news stories } \\
\text { aimed at tobacco workers and healthcare providers. }\end{array}$ \\
\hline Economic impact & US $\$ 250$ for outpatient treatment; $\$ 566$ for hospital admission; $\$ 2041$ for intensive care. Plus lost income and productivity. \\
\hline
\end{tabular}

Adapted from McKnight. ${ }^{7}$

should avoid harvesting in the rain or should begin harvesting after the dew evaporates. ${ }^{1}$ Plastic aprons and rainsuits, in addition to boots and socks, ${ }^{15}$ have been used to reduce exposure to nicotine. ${ }^{23}$ These actions must be weighed against the increased risk of heat stress caused by wearing impermeable clothing in hot weather. ${ }^{1516}$ Additionally, dimenhydrinate is useful in treating GTS once onset has occurred and as a prophylactic measure before harvesting tobacco. ${ }^{18}$ The CDC advises tobacco farm operators to inform their employees of the hazards associated with harvesting wet tobacco and the importance of safe work practices in preventing GTS, ${ }^{20}$ but it is unclear how many operators take such action. Mechanisation of tobacco harvesting will reduce skin contact with wet tobacco leaves and represents a potential method for prevention, although equipment for mechanical harvesting is not accessible to smaller farm operations.

PUBLIC HEALTH RESPONSE

Very little regulatory effort has been undertaken to address the potential hazards of GTS. Currently, there is no legal requirement that workers be informed about the hazards of nicotine exposure. ${ }^{31}$ In Kentucky in 1992, for example, an Occupational Health Nurses in Agricultural Communities study of GTS was undertaken to educate tobacco workers and healthcare providers about the dangers inherent in tobacco harvesting. ${ }^{2}$ The educational effort included targeted informational mailings and news stories in the local media, coinciding with the tobacco harvest. Following a public awareness campaign, the 1993 incidence of hospital-treated GTS increased from the previous year, probably due to the heightened awareness about GTS on the part of tobacco workers and healthcare providers. This study suggests that in the absence of an educational intervention, the magnitude of GTS may not be fully recognised.

\section{Conclusions}

The table summarises what is currently known about GTS. The toxic agent, exposure environment, exposure attributes, symptoms, illness onset, duration of illness, treatment, risk reduction, potential public health responses, and economic impact are identified. The mag- nitude of GTS is not well understood. Unfortunately, surveillance systems have been instituted in only a few states and most published research on GTS is descriptive studies. Treatment is discussed rarely and the magnitude of GTS has not been assessed in sufficient detail. Much of the research cites the same few studies completed many years ago, most of which were conducted in the United States. As the tobacco industry expands production capabilities to the developing world, greater numbers of workers will be exposed to GTS and thus international studies of GTS are badly needed. For example, worldwide output of flue-cured tobacco has nearly tripled over the past 30 years, although the American contribution to the world market has dropped nearly $35 \%$. $^{32}$

In addition, there has been no research to determine whether repeatedly contracting GTS over an extended period of time will increase the risk of cardiovascular disease, cancer, or other diseases. Similarly, the effects of showering and frequent changes of clothing on the development of GTS have not been adequately evaluated. Some workers in India and Kentucky thought that it was impractical and uncomfortable to wear the recommended protective clothing and thus additional prevention strategies need to be evaluated. Because tobacco workers sometimes call poison control centres when experiencing this illness, ${ }^{6}$ improved surveillance through these centres is needed. Part of the problem stems from the fact that treatment costs for GTS may be a significant barrier for poorer workers, especially those without insurance. Ballard and colleagues point out that the number of migrant and foreign workers harvesting tobacco in the United States is increasing. ${ }^{3}$ Because most of the recent research has focused on reports from hospital-treated cases, ${ }^{32}$ GTS incidence is likely to be underestimated. Furthermore, one study found that even though people may be aware of a treatment center's existence, they may not be aware of the services that the centre provides. ${ }^{17}$ As a result, those most in need are unable to obtain treatment.

Considering that tobacco is grown in more than 100 countries and 25 producers account for $90 \%$ of global production, ${ }^{33}$ an international 
public awareness campaign on GTS should be undertaken, and more aggressive worker protection regulations should be promulgated. Healthcare providers in tobacco-growing regions should document in medical records whether or not moisture was present while workers were handling tobacco, the number of hours worked before symptom onset, and the specific ways in which tobacco was handled. ${ }^{6}$ The challenge for public health professionals is to ensure that as market forces and tobacco company practices change the landscape of tobacco production, we monitor, and reduce, the largely hidden problem of GTS.

This report was supported by grant NIH RO1 CA67838-02 from the National Cancer Institute.

1 Gehlbach SH, Williams WA, Perry LD, et al. Green-tobacco sickness: an illness of tobacco harvesters. $\mathcal{F A M A ~} 1974$ 229:1880-3.

2 Boylan, BB, Brandt V, Muehlbauer J, et al. Green tobacco sickness in tobacco harvesters-Kentucky, 1992. MMWR 1993;42:237-40.

3 Ballard T, Ehlers J, Freund E, et al. Green tobacco sickness: occupational nicotine poisoning in tobacco workers. Arch Environ Health 1995;50:384-9.

4 Edmonson WD, Smith BD, Morgan HJ. Green tobacco sickness (bradycardia in a young farmer). F Tenn Med Assoc 1996;89:85-6.

5 Ghosh SK, Parikh JR, Gokani VN, et al. Studies on occupational health problems during agricultural operation of tional health problems during agricultural operation

6 McKnight R, Levine EJ, Rodgers GC. Detection of green tobacco sickness by a regional poison control center. Vet Hum Toxicol 1994:36:505-10.

7 McKnight RH, Koetke CA, Donnelly C. Familial clusters of green tobacco sickness. F Agromed 1996;3:51-9.

8 Hipke M. Green tobacco sickness. Southern Med $\mathcal{F}$ 1993;86:989-92.

9 Geiger B. Tobacco a winner in health care reform. Philadelphia Inquirer 1994 Aug 19:A2

10 Williams B. Brazil: the new tobacco capital. Winston-Salem (North Carolina) 71995 Apr 17:B1

11 Weizenrecker R, Deal WB. Tobacco cropper's sickness. F Fla Med Assoc 1970;57:13-14

12 Misumi J, Koyama W, Miura H. Two cases of "green tobacco sickness" in the tobacco harvesters and the absorption of nicotine through the skin in the rat. $\not p n f$ Indust Health 1983;25:3-9.

13 Gehlbach SH, Williams WA, Perry LD, et al. Nicotine absorption by workers harvesting green tobacco. Lancet $1975 ; \mathbf{i}: 478-80$.
14 Ghosh S, Saiyed HN, Gokani VN, et al. Occupational health problems among workers handling Virginia tobacco. Int problems among workers handling

15 Ghosh S, Gokani VN, Parikh JR, et al. Protection against "green symptoms" from tobacco in Indian harvesters: a preliminary intervention study. Arch Environ Health 1987; 42:121-3.

16 Ghosh S, Gokani VN, Doctor PB, et al. Intervention against "green symptoms" among Indian tobacco harvesters. Arch Environ Health 1991;46:316-17.

17 McKnight RH, Dawson SK, Westneat SC, et al. Delay among the general public in tele

18 Ives TJ. Use of dimenhydrinate in the treatment of green tobacco sickness. Drug Intelligence Clin Pharm 1983; 17:548-9.

19 Grise VN. US tobacco farming trends. Tobacco situation and outlook (US Department of Agriculture) 1995;TBS230 (Dec):34-7.

20 Chaplin JF, Miner GS, Production factors affecting chemical components of the tobacco leaf. Recent Adv Tobacco Sci 1980;6:3-63.

21 Tso TC. Production, physiology, and biochemistry of the tobacco plant. Beltsville, Maryland: Ideals, 1990.

22 Burton HR, Dye NK, Bush LP. Relationship between tobacco-specific nitrosamines and nitrate from different air-cured tobacco varieties. F Agric Food Chem 1994; 42:2007-11.

23 Gehlbach SH, Williams WA, Freeman JI Protective clothing as a means of reducing nicotine absorption in tobacco harvesters. Arch Environ Health 1979;34:111-14.

24 McKnight RH, Kryscio RJ, Mays JR, et al. Spatial and temporal clustering of an occupational poisoning: the example of green tobacco sickness. Stat Med 1996;15:747-57.

25 Sosnowski T. Baling. Tobacco Int 1997;Oct:56-8.

26 Goldfrank L, Melinek M, Blum A. Nicotine. Hosp Phys 1980;1:22-35.

27 Faulkner JM. Nicotine poisoning by absorption through the skin. $\mathcal{F A M A}$ 1933;100:1664-5.

28 Svenson CK. Clinical pharmacokinetics of nicotine. Clin Pharmacokinet 1987;12:30-40.

29 Taylor P. Agents acting at the neuromuscular junction and autonomic ganglia. In: Hardman JG, Gilman AG, Limbird autonomic ganglia. In: Hardman JG, Gilman AG, Limbird therapeutics. New York: McGraw-Hill, 1996.

30 US Department of Health and Human Services. NIOSH US Department of Health and Human Services. NIOSH ers for Disease Control and Prevention, National Institute for Occupational Safety and Health, 1993.

31 Office of the Federal Register, Code of Federal Regulations. Occupational safety and health administration standards. Washington, DC: Office of the Federal Register, National Archives and Records Administration, 1992.

32 Obermayer JB. In support of tobacco: quotas and price supports perpetuate an arcane system that has vanished for other crops. Raleigh (North Carolina) News and Observer 1996; Jun 23:1F.

33 World Health Organisation. Tobacco or health: a global status report. Geneva, Switzerland: World Health Organisation, 1997. 